8. Kobyletzke, von D.: Ubertritt und elimination von präpratal dem neugeborenen zugeführten medikamenten. Monatsschr. Kinderheild., 116: 250 (1968).

9. McHenry, M. C., Gavan, T. L., Gifford, R. W., Jr., Geurkink, N. A., Van Ammen, R. A., Town, M. A., and Wagner, J. G.: Adjustments based on endogenous creatinine clearance and serum creatinine concentration. Ann. Int. Med., 74: 192 (1971).

10. Morris, J. A., Hustead, R. F., Robinson, R. G., and Haswell, G. L.: Measurement of feto-placental blood volume in the human previable fetus. Amer. J. Obstet. Gynecol., 118: 927 (1974).

11. Rebattu, J. P., Lesue, G., and Megard, M.: Streptomy cine, barriere placentaire troubles cochleo-vestibularies. J. Franc. Otorhinolaryngol., 9: 411 (1960).

12. Streeter, G. L.: Weight, sitting height, head size, foot length, and menstrual age of the human embryo. Contrib. Embryol. Inst., II: 143 (1921).

13. Wynn, R. M.: Morphology of the placenta. In: N.S. Assalii: Biology of Gestation, p. 103 (Academic Press, New York, 1968).
14. Yoshioka, H., Monma, T., and Matsuda, S.: Placental transfer of gentamicin. J. Pediat., 80: 121 (1972).

15. Difco Labs, Detroit, Mich.

16. American Optical Corp., Scientific Instrument Division, Buffalo, N.Y.

17. The authors wish to express their appreciation to Ms. Patricia Ludwig for her expert technical assistance.

18. This work was supported by United States Public Health Service Grants nos. GM 15956 and HD 02528.

19. The present address of Dr. J. A. Morris is: Department of Obstetrics and Gynecology, Charles R. Drew Postgraduate Medical School, Los Angeles, Calif. 90059 (USA).

20. Requests for reprints should be addressed to: R. E. Kauffman, M.D., Department of Pediatrics, University of Kansas School of Medicine, 39th and Rainbow Blyd., Kansas City, Kan., 66103 (USA).

21. Accepted for publication September 20, 1974.

Copyright (c) 1975 International Pediatric Research Foundation, Inc.

Printed in U.S..4.

Pediat. Res. 9: 107-110 (1975)

Distal latency time

full term infant

intrauterine growth retardation nerve transmission term infant

\title{
Acceleration of the Median Nerve Distal Latency Time in Preterm Infants with Intrauterine Growth Retardation
}

\author{
DONALD W. THIBEAULT, ${ }^{(13)}$ VIRGIL LAUL, AND HUBERT GULAK \\ Laboratory for Perinatal Research, Departments of Pediatrics and Physical Medicine, Harbor General \\ Hospital, UCLA School of Medicine, Torrance, California, USA
}

Extract

The distal latency time (DLT) of the median nerve was measured in infants at various stages of in utero and ex utero maturation.

The DLT measured at $36^{\circ}\left(\mathrm{DLT}_{36}\right)$ during the first 3 days of life was inversely related to gestational age in normal preterm infants. However, the DLT $_{36}$ was significantly accelerated in infants with in utero growth retardation (IUGR).

In normal infants the DLT $_{36}$ was significantly related to the nerve conduction velocity of the proximal segment of the median nerve. This relation was lost in infants with IUGR, since the $\mathrm{DLT}_{36}$ was accelerated but not the nerve conduction velocity.

In normal preterm infants the slope of change of $\mathrm{DLT}_{36}$ in utero with maturation was similar to the change ex utero. With IUGR the $\mathrm{DLT}_{36}$ shortened sharply during the first 2 weeks of postnatal life, and thereafter the $\mathrm{DLT}_{36}$ changed at the same rate as in normal infants.

The DLT is sensitive to temperature change in the thenar muscle. The more immature the infant the greater the change of DLT with temperature.

Apnea in preterm infants was not significantly related to the $\mathrm{DLT}_{36}$
Speculation

Intrauterine growth retardation accelerates the DLT of the median nerve but not the nerve conduction velocity of the proximal nerve. This study focused only on DLT changes with severe intrauterine growth retardation compared with normal preterm and term infants. Acceleration of the DLT may be a useful index of chronic stress in utero not associated with severe growth retardation.

The mechanism of apnea, a cornmon clinical complication in premature infants, is poorly understood. However, its frequent association with generalized muscle weakness suggests that interference with transmission of impulses in the neuromuscular junction may play a role. The neuromuscular junction in normal full term and large preterm infants operates with diminished reserves $(6,10)$, and in some respects resembles that of adult myasthenia gravis (2).

Nerve conduction velocities (NCV) in proximal peripheral motor nerves have been extensively studied and correlate significantly with gestational age, but are not influenced by multiple births or intrauterine and postnatal metabolic derangements (4-9). There has been only one study on the conduction time in the distal branches of the peripheral nerves (distal latency time (9), and this was with full term infants. It 
would be interesting to know whether the DLT is accelerated in preterm infants with intrauterine growth retardation.

It is the purpose of this study to measure in premature infants the combined times of conduction in the peripheral branches of the median nerve and neuromuscular transmission time at various gestational ages. This time will be correlated with the proximal peripheral motor nerve conduction velocity, intrauterine growth, and apnea in the preterm and term infant.

\section{MATERIALS AND METHODS}

Sixteen full term and 44 preterm infants were studied; of the latter group, 12 had varying degrees of respiratory distress syndrome. The study infants were divided into two groups: normal infants and those with in utero growth retardation (less than 10 th percentile for body weight). The gestational age was calculated from the last menstrual period and was also assessed by the method of Dubowitz et al. (3). The gestational age of all study infants calculated by the two methods did not differ by more than 2 weeks.

All infants were studied in incubators or a heat-controlled environment (11). All preterm infants were cared for in an intensive care unit and those ill or at high risk were monitored with blood gas measurements and cardiorespiratory monitoring equipment. The total number of bradycardic (heart rate $<100 / \mathrm{min})$ and apneic episodes $(\geqslant 20 \mathrm{sec})$ were recorded at the time of occurrence by the nursing staff and totaled for each day.

Subjects were not studied if (1) the $\mathrm{pH}$ of arterial blood was less than 7.2 or greater than $7.5,(2) \mathrm{P}_{\mathrm{CO}_{2}}$ less than $25 \mathrm{~mm} \mathrm{Hg}$ or greater than $55 \mathrm{~mm} \mathrm{Hg}$, or (3) serum calcium less than 7.0 $\mathrm{mg} / 100 \mathrm{ml}$. The serum sodium and potassium were in the normal range and magnesium had not been given to the mothers in the intrapartum period. Serum magnesium levels were not measured.

The median nerve was stimulated with surface electrodes at two points along its length, proximal to the elbow and at the wrist. The stimulus consisted of square wave impulses of supramaximal intensity of $0.05-\mathrm{msec}$ pulse duration. The muscle action potential evoked in the thenar muscle was recorded from an intramuscularly positioned 0.5 -inch Tefloncoated electromyograph needle with a $1-\mathrm{mm}$ exposed tip with standard 0.5-inch EEG electrodes for the reference and ground. The proximal latency time and DLT were determined by measuring the time interval between the moment of each stimulation and the moment of occurrence of the muscle action potential of the thenar muscles (Fig. 1). The distance between the two points of stimulation was divided by the

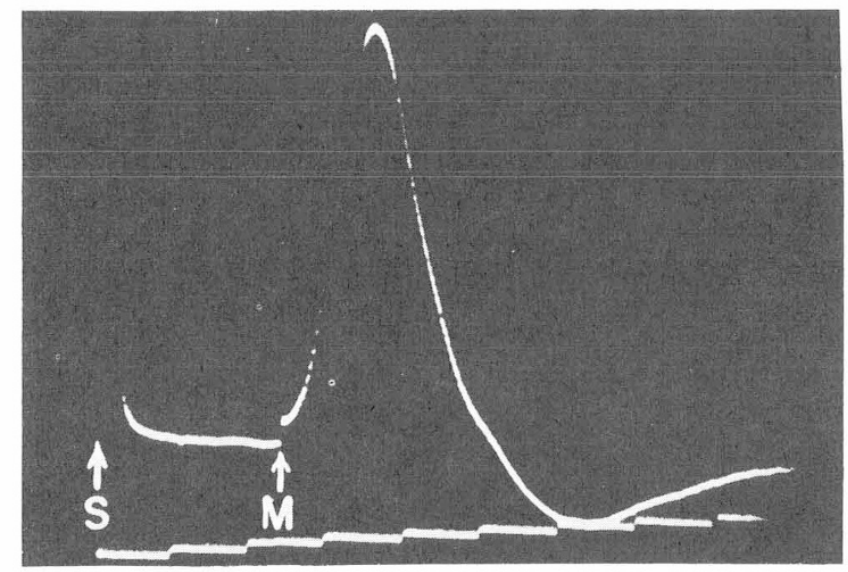

Fig. 1. The distal latency time is the time from stimulus $(S)$ to the start of the muscle twitch $(M)$. The bottom line is the time signal, and each interrupted line is a $1-\mathrm{msec}$ interval. The distal latency time in this infant of 31 weeks of gestational age at 6 days of postnatal age is 2.5 msec. difference between the two latencies to obtain the conduction velocity of motor fibers $(\mathrm{NCV})$ in the intervening segment of the nerve.

In each subject the recording electrode in the thenar muscle was repositioned during the experiment to produce the shortest DLT. The mean of the six shortest DLT was reported. The maximum variation of the DLT was $0.2 \mathrm{msec}$. The latencies were measured directly from the display with a calibrated time marker or photographed and subsequently analyzed. The DLT and NCV were measured 115 times in the first 3 days of life. Fifty-four DLT and NCV measurements were obtained during the postnatal period until discharge in infants with gestational ages of 27-29 weeks to establish the rate of DLT and NCV change during postnatal life.

Repetitive stimulation of 5 stimuli/sec (for $10 \mathrm{sec}$ ) of supramaximal intensity was delivered to the distal median nerve at the wrist and the amplitudes of the responses were observed and recorded. Post-tetanic single stimulations were not assessed.

The intramuscular temperature of the thenar muscle was measured with a copper-constantan thermocouple enclosed in the tip of a 21-gauge needle. The surface temperature was also measured with a copper-constantan thermocouple. These temperatures were read from an Omega $T_{4}$ electronic thermometer (12), which was calibrated with a certified laboratory thermometer with $0.1^{\circ}$ accuracy. Studies were performed when the two temperatures agreed within $1^{\circ}$. Temperatures recorded in this study refer to the mean of the two sites. The effect of temperature variation between $30^{\circ}$ and $40^{\circ}$ on the DLT was measured in 51 studies on 21 infants. A minimum of four different temperatures and the corresponding DLT were assessed in each study. The temperature of the thenar muscle was varied with hot or cold packs surrounding the hand and wrist. Because temperature significantly influenced the DLT, all DLT values were expressed in references to $36^{\circ}\left(\mathrm{DLT}_{36}\right)$. The temperature of the forearm was not controlled.

No untoward complications such as local infection, induction of apnea, or bradycardia occurred during the study.

\section{RESULTS}

Figure 2 shows the relation of distal latency time measured at $36^{\circ}\left(\mathrm{DLT}_{36}\right)$ in the first 3 days of life to gestational age. All values of $\mathrm{DLT}_{36}$ in the first 3 days are plotted as one group since the $\mathrm{DLT}_{36}$ did not changed significantly during this period. The $\mathrm{DLT}_{36}$ is inversely related to gestational age and increases sharply in infants less than 33 weeks. The largest scatter of $\mathrm{DLT}_{36}$ occurred in the low gestational age infants (27-32weeks) with some attaining $\mathrm{DLT}_{36}$ comparable to infants of high gestational age.

Figure 3 shows the relation of $\mathrm{DLT}_{36}$ to gestational age after separating the infants into two groups: normal and IUGR. The difference between the groups are most significant in the $<32$ weeks of gestational age groups, which is the time period that the $\mathrm{DLT}_{36}$ normally undergoes the greatest change.

Table 1 shows the correlation between $\mathrm{DLT}_{36}$ and nerve conduction velocity of the proximal segment of the median nerve. When infants of all gestational ages were considered, the $\mathrm{DLT}_{36}$ in the first 3 days of life is significantly correlated with the nerve conduction velocity in both the normal and IUGR groups. However, in the IUGR group of $\leqslant 32$ weeks of gestational age, the $\mathrm{DLT}_{36}$ does not relate significantly to the nerve conduction velocity. In the latter group the nerve conduction velocity of the normal and IUGR groups are not significantly different $(P>0.1)$. Thus, infants with IUGR have accelerated $\mathrm{DLT}_{36}$, but their nerve conduction velocities are similar to those of normal infants.

Figure 4 shows the change of $\mathrm{DLT}_{36}$ postnatally as compared with the changes of $\mathrm{DLT}_{36}$ during in utero maturation. In the normal group the slope of change of 


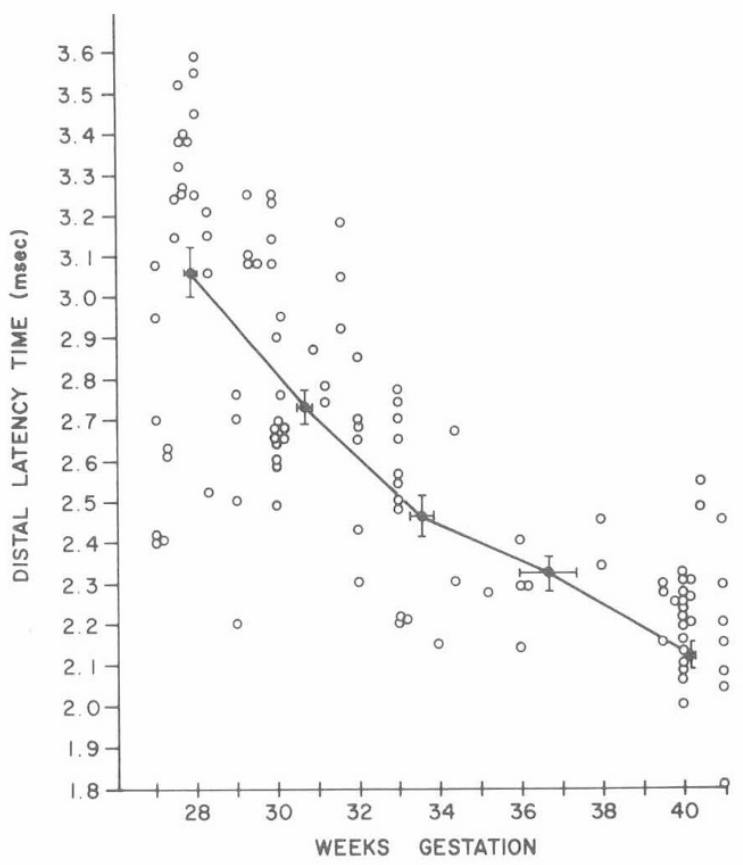

Fig. 2. The relation of the distal latency time of the median nerve measured at $36^{\circ}$ to gestational age during the first 3 days of life. Vertical and horizontal bars indicate mean \pm SE. Data are averaged by 3-week intervals; the first group includes infants of 27,28 , and 29 weeks of gestational age and the oldest, of 39,40 , and 41 weeks of gestational age.

$\mathrm{DLT}_{36}$ in utero is similar to that ex utero. In the IUGR group the $\mathrm{DLT}_{36}$ shortens sharply during the first 2 weeks of postnatal life; however, the slopes did not differ significantly thereafter in the in utero and ex utero courses.

Table 2 shows the effect of temperature change in the thenar muscles (between $30^{\circ}$ and $40^{\circ}$ ) on the DLT in three gestational age groups. The normal full term infant will prolong the DLT $0.072 \mathrm{msec}$ for each $1^{\circ}$ decrease of the thenar muscle group $\left[\left(-1^{\circ}\right)\left(-0.072 \frac{\mathrm{msec}}{\left.{ }^{\circ} \mathrm{C}\right)}=0.072 \mathrm{msec}\right]\right.$. The most immature infants have the greatest change in DLT per change in temperature but by 30-32 weeks of gestational age the change is similar to the full term.

Repetitive stimulation to the distal median nerve at the wrist at 5 impulses/sec (for $10 \mathrm{sec}$ ) showed no decrease in the amplitude of the response.

Apnea in the preterm infants was not significantly related to the $\mathrm{DLT}_{36}$. Many of the premature infants had hypocalcemia $(<7.0 \mathrm{mg} / 100 \mathrm{ml})$ in the first day which was corrected to $>7$ $\mathrm{mg} / 100 \mathrm{ml}$ with intravenous calcium infusion before DLT measurement. The level of calcium in blood did not appear to influence the $\mathrm{DLT}_{36}$.

Table 1. Correlation of nerve conduction velocity to distal latency time in first 3 days of life

\section{No.}

Subject

No. measure- Correlation

infants ments coefficient $P$

\begin{tabular}{lllll}
\hline All infants & & & & \\
$\quad$ Normal & 37 & 69 & 0.883 & $<0.001$ \\
$\quad$ IUGR & & & \\
Preterm infants, 27-32 & 23 & 40 & 0.775 & $<0.001$ \\
$\quad$ wk gestational age & & & & \\
$\quad$ Normal & 19 & 37 & 0.674 & $<0.001$ \\
$\quad$ IUGR & 14 & 22 & 0.323 & $>0.1$
\end{tabular}

${ }^{1}$ Intrauterine growth retardation.

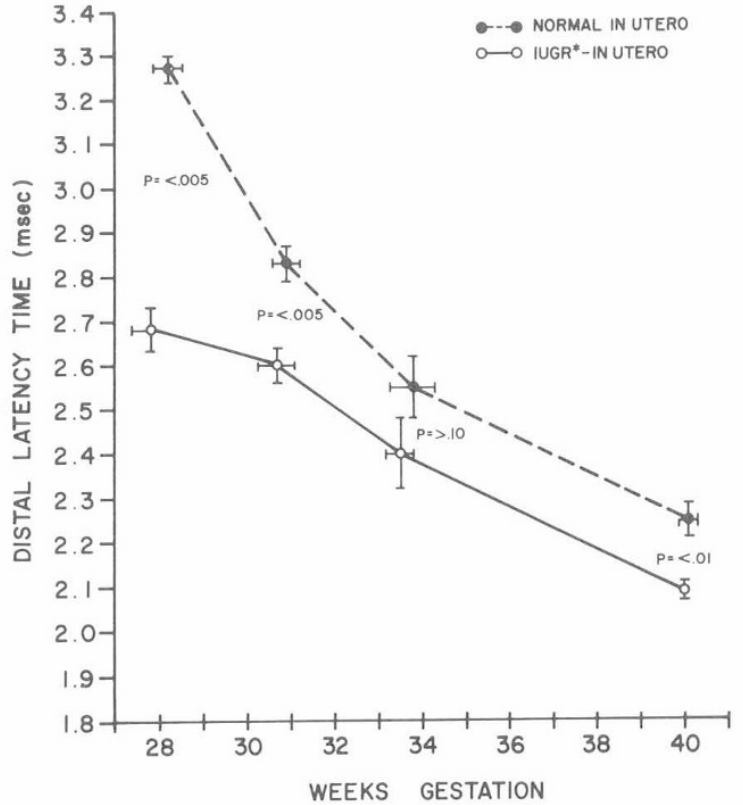

Fig. 3. The relation of the distal latency time of the median nerve measured at $36^{\circ}$ to gestational age during the first 3 days of life. The lower curve includes those infants with in utero growth retardation. The upper curve includes the normal infants. The $36-38$ week group is omitted because of insufficient numbers. $P$ values refer to unpaired student $t$ tests between normal and intrauterine growth-retarded (IUGR) groups.

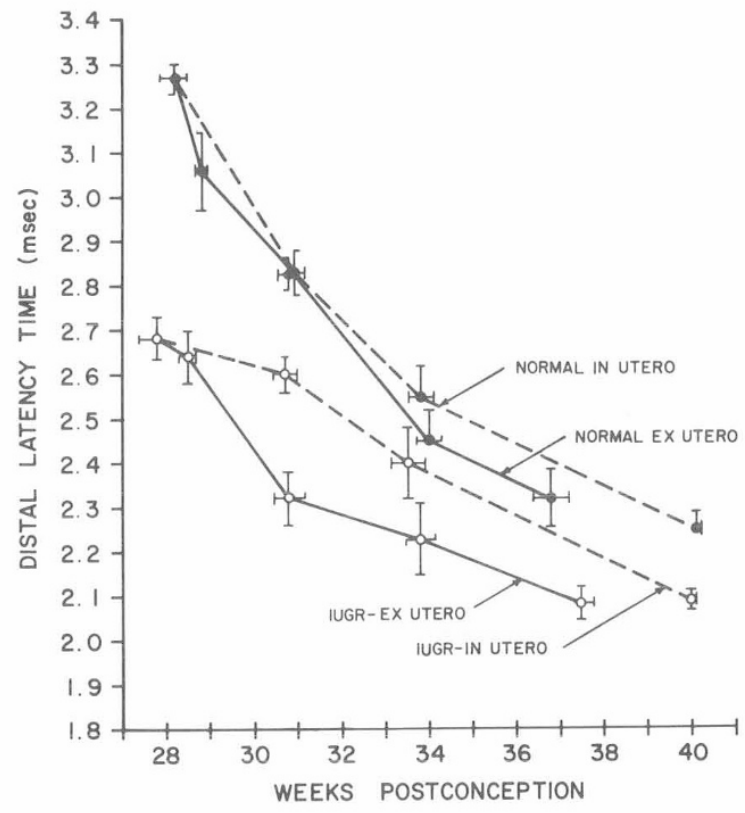

Fig. 4. The relation of the change in distal latency time at $36^{\circ}$ $\left(\mathrm{DLT}_{36}\right)$ after birth to the change of $\mathrm{DLT}_{36}$ in utero. The upper curve shows DLT $_{36}$ (normal group) measured in the first 3 days of life at different gestational ages. The second curve from the top follows the $e x$ utero change in $\mathrm{DLT}_{36}$ in the 27-29 weeks (normal group) of gestational age group. The lower two curves are similar to the above except the subjects had intrauterine growth retardation. IUGR: intrauterine growth retardation.

\section{DISCUSSION}

Nerve conduction velocities of peripheral motor nerves have been repeatedly measured in newborn full term and preterm infants and they provide an accurate measure of gestational age $(1,4,5,7-9)$. The conduction velocities, in addition, are 
Table 2. Correlation of temperature change in thenar muscle to distal latency time (DLT) of normal and intrauterine growth-retarded (IUGR) newborn infants

\begin{tabular}{|c|c|c|c|c|c|c|}
\hline $\begin{array}{l}\text { Subjects and } \\
\text { gestational ages }\end{array}$ & $\begin{array}{l}\text { No. } \\
\text { infants }\end{array}$ & $\begin{array}{l}\text { No. } \\
\text { studies }\end{array}$ & $\begin{array}{c}\text { No. } \\
\text { measure- } \\
\text { meants }\end{array}$ & $\frac{\Delta D L T(m s e c)^{1}}{\Delta \operatorname{Temp}\left({ }^{\circ} \mathrm{C}\right)}$ & Correlation coefficient & $P$ \\
\hline Normal, 30-32 wk & 4 & 8 & 35 & -0.073 & 0.739 & $<0.001$ \\
\hline IUGR, 30-32 wk & 3 & 6 & 25 & -0.073 & 0.770 & $<0.001$ \\
\hline Normal, 27-29 wk & 5 & 10 & 55 & -0.107 & 0.770 & $<0.001$ \\
\hline
\end{tabular}

${ }^{1}$ The slope $\frac{\mathrm{DLT}(\mathrm{msec})}{\text { temp }\left({ }^{\circ} \mathrm{C}\right)}$ was established by linear regression analysis.

not influenced by intrauterine growth retardation or metabolic abnormalities in the newborn period $(7,8)$.

The DLT is dependent not only on nerve conduction velocity in the distal branches of the median nerve, but also on the time for neuromuscular junction transmission and for the muscle to respond to depolarization of the end plate. The present study shows that with a normal pregnancy the distal latency time is significantly correlated with gestational age and also with the nerve conduction velocity of the proximal median nerve. Unlike the nerve conduction velocity, the DLT can be influenced by intrauterine events associated with IUGR.

The cause of accelerated shortening of the DLT in preterm infants with IUGR cannot be determined by this study. However, since normal preterm infants and those with IUGR had similiar proximal nerve conduction velocities, it seems unlikely that conduction velocities in the distal nerve branches would differ. It is possible that the factors which induced intrauterine growth retardation could also provide the stress factors to accelerate the maturation of enzyme systems responsible for transmission of nerve impulses at the myoneural junction. However, with our methodology, a difference in myoneural junction function between normal preterm infants and those with IUGR could not be demonstrated. A more rapid response of the muscle membrane to depolarization at the end plate could also shorten the DLT in infants with IUGR.

The initiation of accelerated shortening of the DLT appears to occur only in utero, inasmuch as normal infants $<30$ weeks of gestational age who are stressed for many days during extrauterine life did not have rapid shortening of their DLT (Fig. 4). However, the intrauterine growth-retarded infant undergoes accelerated shortening of the DLT over a 2-week period postnatally. This relatively rapid shortening of the DLT suggests an enzymatic maturation. Further shortening of the DLT could be limited by the slow transmission in the distal branches of the median nerve.

The DLT is sensitive to temperature changes and is particularly more so with the youngest infants. Any studies on myoneural junction function will therefore require temperature control. The influence of temperatures on nerve conduction velocity is thought not to be important in full term and large premature infants $(1,9)$; however, its influence has not been studied in small premature infants but because of the small amount of subcutaneous tissue, temperature variations may be of considerable importance.

Apnea in premature infants was not significantly correlated with the DLT. The onset of apnea was usually at $72-120 \mathrm{hr}$ of age and not in the first days when the DLT was slowest. Also apnea persisted in infants less than 30 weeks of gestational age as the DLT accelerated.

\section{SUMMARY}

The distal latency time of the median nerve (DLT) was measured for the first time in preterm infants. The DLT was significantly shortened in those infants with intrauterine growth retardation.

\section{REFERENCES AND NOTES}

1. Blom, S., and Finnström, O.: Motor conduction velocities in newborn infants of various gestational ages. Act Paediat. Scand., 59: 377 (1968).

2. Churchill-Davidson, H. C., and Wise, R. P.: Neuromuscular transmission in the newborn infant. Anesthesiologist, 24: 271 (1963).

3. Dubowitz, L., Dubowitz, V., and Goldberg, C.: Clinical assessment of gestational age in the newborn infant. J. Pediat., 77: 1 (1970)

4. Gamstorp, I.: Normal conduction velocity of ulnar, median and personeal news in infancy. Acta Paediat. Suppl., 146: 68 (1963).

5. Koenigsberger, M. R., Curtin, J., and Lovelace, R. E.: Motor conductive velocities as a measure of gestational age in premature infants: A study of multiple births-twins, triplets and quadruplets (Abstract). 22nd Annual Meeting of the American Academy of Neurology, Bal Harbour, Florida, p. 53, 1970.

6. Koenigsberger, M. R., Patten, B. M., and Lovelace, R. E.: Studies of myoneural junction in fullterm, prematures and hypermagnesemic newborn infants (Abstract). Pediat. Res., 7: (1973).

7. Moosa, A.: Further studies of motor nerve conduction velocity in newborn infants. Arch. Dis. Childhood, 44: 782 (1969)

8. Moosa, A., and Dubowitz, V.: Postnatal maturation of peripheral nerves in preterm and fullterm infants. J. Pediat., 79: 915 (1971).

9. Thomas, J., and Lambert, E. H.: Ulnar nerve conduction velocity and H-reflex in infants and children. J. Appl. Physiol., 15: 1 (1960).

10. Wise, G. A., and McQuillen, M. P.: Transient neonatal myasthenia Arch. Neurol., 22: 556 (1970).

11. Sierracin Cradle Warmer, The Sierracin Corp., Burbank, Calif.

12. Omega Engineering, Stamford, Conn.

13. Requests for reprints should be addressed to: D. W. Thibeault, M.D., The Department of Pediatrics, Harbor General Hospital, 1000 W. Carson St., Torrance, Calif. 90509 (USA).

14. Accepted for publication September 16, 1974. 